\title{
Epizootology and Molecular Diagnosis of Lumpy Skin Diesease Among Livestock in Azerbaijan
}

\author{
Shalala K. Zeynalova* \\ virology, Republican Veterinary Laboratory, Baku, Azerbaijan
}

\section{Introduction}

Lumpy skin disease (LSD) is a cutaneous disease of livestock caused by a DNA-containing virus belonging to Poxviridae family called Lumpy Skin Disease Virus (LSDV). Another name of the virus is Neethling. The disease is characterized mainly by fever, and lesions appearing on the skin. The incubation period is 6-9 days. Mortality of the disease is about $10 \%[1,2]$, however, secondary infection of lesions can increase the mortality rate. LSD was first recorded in Zambia, South Africa, then spread to Sudan, Nigeria and European countries. According to information provided by OIE, LSD outbreaks also have spread in Middle Eastern countries including Turkey, where it has been considered endemic since 2007-2008 [1]. An outbreak of LSD was also reported in Iran in 2013-2014 [1, 2].

Signs of LSD in Azerbaijan were recorded for the first time in the Region (rayon) of Bilasuvar in May of 2014 and reported to OIE [3]. LSD was quickly suspected, as Bilasuvar neighbors Iran which had recently reported LSD. The same clinical signs were subsequently recorded in cattle in the regions of Jalilabad, Aghdash and Udjar. Some of the cases resulted in death. A PCR assay was set up in the Republican Veterinary Laboratory in Azerbaijan in order to test livestock samples for the disease while an epizootological study was conducted to determine the extent of disease spread within the three affected rayons.

\section{Methods}

Samples from lungs and abdomen, and head and neck lesions were taken from animals in the regions of Aghdash, Udjar, Jalilabad and Bilasuvar were sent to the Republican Veterinary Laboratory (RVL) for testing. Suspensions were prepared from the samples, and extraction was performed using a DNeasy blood mini kit (Qiagen, Stanford, CA), following the manufacturer's instructions.

Specific forward and reverse Capripox primers were used for master mix preparation [4] including Forward primer: 5'-TCCGAG-CTC-TTT-CCT-TAC-TAT-3', Reverse primer: 5'-TATGGT-ACC-TAA-ATT-ATA-TAC-GTA-AAT-AAC-3', and Probe: 5' 6FAMCAATGgGtaAAAgAtTtCTAMGBNFQ 3'. Positive Template Control consisted of 5' ATG GCG ATG TCC ATT CCC TGA CCA ATG GGT AAA AGA TTT CTA TCG TAA CAG ATG AAA GAG CAA GCT ACT ATT CCT CAC GGA AAT GAA ATG CTT C 3'.

Taq DNA Polymerase, 10X PCR buffer, $50 \mathrm{mM} \mathrm{MgCl} 2$, and 10 $\mathrm{mM}$ dNTPs were used to prepare the master mix according to the protocol described [4]. Samples and negative and positive template controls were added to the prepared master mix, and the reaction was run on a Light Cycler 2.0 PCR instrument using the thermocycling conditions used by Balinsky et al. [4]

\section{Results}

The LSDV PCR set up by the virology department of the RVL was able to confirm the presence of LSDV in cases from Bilasuvar, Jalilabad, Udjar and Aghdash. From 2822 susceptible cattle with LSD lesions, 33 animals died (1.2\%). The 255 animals that tested were positive by PCR. The surviving 2567 animals were treated. Lesions of the animals exposed to LSDV were disinfected using detergent iodine. Appropriate preventative measures were put in place. The epizootological status is currently stable, and the virus is now considered endemic in the Azerbaijan Republic.

Keywords

LSD; PCR; lumpy skin diseases

\section{Acknowledgments}

The authors are grateful to Ketan Patel and Matthew McGillicuddy of the Naval Medical Research Center at Fort Detrick, Maryland, for generously providing the reagents for the assay and to Cooperative Biological Engagement Program (CBEP) personnel in Azerbaijan: Sebastian McClendon for technical assistance with the Capripox assay, and April Johnson and Saida Aliyeva for support with publication development and submission.

\section{References}

1.LUMPY SKIN DISEASE NB OIE Terrestrial Manual 2010, 1, C H A P T E R 2.4.1 4

http://osp.mans.edu.eg/elsawalhy/Inf-Dis/LSD.htm

2.SCIENTIFIC OPINION Scientific Opinion on lumpy skin disease 1 EFSA Panel on Animal Health and Welfare (AHAW)2,3 EFSA Journal 2015;13(1):3986 European Food Safety Authority (EFSA), Parma, Italy

http://www.google.com/url?sa $=$ t\&rct $=\mathrm{j} \& \mathrm{q}=\& \mathrm{esrc}=\mathrm{s} \& \mathrm{frm}=1 \&$ source $=$ web\&cd $=1 \&$ ved $=0$ CB0QFjAA\&url $=\mathrm{http} \% 3 \mathrm{~A} \% 2 \mathrm{~F} \% 2 \mathrm{Fwww}$.efsa. europa.eu\%2Fde\%2Fefsajournal\%2Fdoc\%2F3986.pdf\&ei=veG8VO D6HJLIsQTRsoLYDg\&usg=AFQjCNE-7Uo2wmL0ktbxyXzeNhL PumKW6w

3.Report OIE LSDV in Azerbaijan 7 July 2014

4.Balinsky C.A., Delhon G., Smoliga G., Prarat M., French R.A., Geary S.J., et al. Rapid preclinical detection of sheeppox virus by a real-time PCR assay // Journal of clinical microbiology 46.2 (2008): 438-442

*Shalala K. Zeynalova

E-mail: zeynalova.shelale@rambler.ru 